\title{
The value of China's ban on wildlife trade and consumption
}

\author{
China's decision to ban the trade and consumption of terrestrial wild animals, while controversial, is a viable \\ response to the COVID-19 pandemic. The ban has implications that extend beyond safeguarding human health to \\ also help combat illegal wildlife trade and protect threatened species.
}

\author{
Lian Pin Koh, Yuhan Li and Janice Ser Huay Lee
}

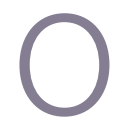
$\mathrm{n}$ the day when millions around the world were ushering in the 2020 New Year, a seafood market in Wuhan, capital city of China's Hubei Province, was abruptly shut down. Animals sold in the market were suspected to be the source of a novel coronavirus that had been transmitted to humans, resulting in an unidentified pneumonia, which the world has come to know as COVID-19.

While this spillover effect from animals to humans has not been definitively established by the scientific community, China has moved swiftly to tackle this route of disease transmission. Following President $\mathrm{Xi}$ Jinping's warning that the consumption of wildlife poses an immense risk to public health, the Standing Committee of the National People's Congress adopted an urgent decision on 24 February 2020 to expand the scope of China's Wildlife Protection Law to ban the consumption of almost all wild animals ${ }^{1-3}$ (Box 1).

\section{A decision unprecedented in scope and scale}

This announcement sent shockwaves around the globe, largely lauding it as an important step in the right direction ${ }^{4}$. China's decision is also unprecedented at several levels, which could result in profound and far-reaching impacts for both humans and wildlife.

First, this decision was initiated and adopted by China's highest legislature the Standing Committee of the National People's Congress - with the explicit endorsement of President $\mathrm{Xi}^{1,2}$. In contrast, China's response to the SARS outbreak in 2003 - a short-lived ban on the trade and consumption of palm civets ${ }^{5}$ - was initiated by various government agencies at lower legislative levels. In responding to the COVID-19 pandemic, the political will in China has never been stronger or more overt across multiple levels of government ${ }^{6}$. Within a few months, all 31 provinces in China have published provincial legislation on wildlife farming and consumption.
Perhaps more importantly, from May to July, the People's Congress standing committees at the national and provincial levels conducted nation-wide evaluations on the effectiveness of these policies and their enforcement. The committees concluded that policies were generally well implemented, but there was room for improvement on certain aspects, including finding alternative livelihoods for affected wildlife traders, continuing to revise the protected species lists, and addressing loopholes in wildlife trade monitoring and habitat conservation. In terms of positive outcomes, joint actions and special operations from the government have closed 12,000 wildlife-related businesses, intensified monitoring efforts to include over four million e-commerce platforms, and removed 990,000 online sources of information associated with wildlife trade ${ }^{6}$.

Second, China's current decision includes a series of new legislations to build on the achievements of current actions by enhancing the regulation of wildlife farms and markets (Box 1). The revision of the country's Wildlife Protection Law is expected to bring about long-term and systematic changes to wildlife conservation. Additionally, China is also revising its List of Protected Animals. Species threatened by consumption, such as the pangolin and yellow-breasted bunting, are being promoted to the highest protection level (Class I Wildlife species) ${ }^{7}$. Furthermore, China's Ministry of Agriculture and Rural Affairs published an updated Catalogue of Animal Genetic Resource in May 2020. Among wild animals, only species in this catalogue can be farmed or consumed ${ }^{8}$. There are 64 species of wild animals that are being farmed for consumption, but are not yet included in this catalogue for various reasons (for example, to reduce the risk of sourcing animals from the wild). Nevertheless, the Ministry of Forestry and Grassland has categorized them into two groups: the farming of 45 species (for example, bamboo rat and civet cat) is due to be banned by the end of 2020, and the remaining 19 species (for example, several species of snakes) are allowed to be farmed for non-consumption uses ${ }^{9}$. Furthermore, the disbursement of government financial compensation to the farmers affected by these new legislations, amounting to over a billion US dollars, is expected to be completed by the end of 2020 .

Third, the current ban is likely to galvanize rapid and widespread knock-on actions and impacts. For example, Guangdong has already banned wild vertebrate animals as pets ${ }^{10}$. The consumption of dogs and cats is banned in the city of Shenzhen ${ }^{11}$. Pangolin scales are removed as a key ingredient in traditional Chinese medicine, although it is still included as an ingredient in patent medicines in the 2020 Chinese Pharmacopoeia ${ }^{12,13}$. The pre-COVID wildlife management system in China, especially in its wildlife farming industry, has long been criticized by conservationists to be disordered and outdated. The lack of incentives and capacities had been a major barrier to change for government agencies in the country. The COVID-19 pandemic, at great human and economic costs, has mainstreamed the discourse of wildlife conservation for human well-being, clarified legislations on what species can be farmed, and provided a policy framework for systematic and enforceable wildlife management and conservation. These actions are exactly what scientists have long called for to minimize the risk of zoonotic disease transmission and outbreaks in the future ${ }^{14}$.

\section{Recognizing risks from previous experience}

Nevertheless, there still are concerns about the long-term effectiveness of the ban ${ }^{15,16}$, as similar interventions in the recent past have been short lived and have resulted in unintended consequences. For example, after the 2003 SARS outbreak, the trade and 


\section{Box 1 | Scope of China's decision on the illegal trade and consumption of wild animals}

China's decision on the illegal trade and consumption of wild animals was adopted at the 16th Meeting of the Standing Committee of the 13th National People's Congress on 24 February 2020. The following information was correct as of 10 December $2020^{1-3,18}$.

China's decision on banning the illegal trade and consumption of wild animals has direct bearing on the country's Wildlife Protection Law, a legislation implemented in 1989 and revised in 2018 to increase state-level protection for China's wildlife. The law covers five chapters and 58 articles and include provisions on wildlife ownership, scope of protection, protection and management mechanisms, and penalties for law violation. Under this law are three lists for species protection at the national level:

- Class I Wildlife species

- Class II Wildlife species

- Wildlife species of strong ecological, scientific or societal value
Apart from the nationally protected species list, each province has a list of locally protected wildlife species.

The decision adopted on 24 February 2020 reinforces wildlife protection by ensuring:

(1) All wild animals protected under the Wildlife Protection Law and other relevant laws of the People's Republic of China are prohibited from being hunted, traded, transported or consumed.

(2) All terrestrial wild animals including those with important ecological, scientific or societal values, and those that are artificially bred or raised, are banned from consumption.

(3) All terrestrial wild animals that naturally grow and reproduce in the wild are also prohibited from being hunted, traded or transported for the purpose of their consumption.

Livestock, poultry and other animals in the Catalogue of
Animal Genetic Resource will continue to be regulated by
China's Animal Husbandry Law
Fish and other aquatic wildlife will continue to be regulated
by China's Fishery Law
Wild plants are not included in the ban
$\begin{aligned} & \text { Animals and animal products for non-edible use, including for } \\ & \text { scientific research, medicinal use and display, will continue to } \\ & \text { be regulated by existing laws, such as the Wildlife Protection } \\ & \text { Law and Traditional Chinese Medicine Law. }\end{aligned}$
$\begin{aligned} & \text { Amphibian and reptilian species, including turtles and } \\ & \text { bullfrogs, listed in the National Catalogue of Economically } \\ & \text { Important Aquatic Plant and Animal Resource and the new } \\ & \text { List of Aquatic Species, are regulated under China's Fishery } \\ & \text { Law, and not included in the ban. }\end{aligned}$
(a)

consumption of palm civets were banned temporarily in China, and farmed civets were culled in Guangdong ${ }^{5}$. That ban was eventually reversed due to pressure from wildlife farmers and traders who suffered severe economic impacts. Wildlife farming quickly resumed, and was even promoted by local officials for job creation and economic recovery. Elsewhere, bushmeat hunting and consumption were banned across
West Africa during the Ebola virus disease outbreak from 2013-2016. The widespread ban deprived many local communities of their primary source of protein and drove the bushmeat trade underground ${ }^{17}$. Hunters and bushmeat traders were most affected by the ban as they were offered no compensation and were not able to take up informal loans to tide over their loss of livelihood since collateral was offered in the form of meat ${ }^{17}$. When the region was officially declared free of Ebola, hunting frequency increased and bushmeat operations resumed openly.

Drawing from these past experiences, critics of China's current decision warn that a singular focus on a wildlife trade ban could do more harm than good, if it disproportionately penalizes small-scale farmers and traders of wild animal protein while failing to provide alternative livelihoods, drives the trade and consumption of wildlife species underground, or overlooks the loss of natural wildlife habitats as an underlying driver of zoonotic disease transmission ${ }^{15,16}$.

\section{The way forward}

Obviously, there is much to be gained from leveraging the unprecedented political will and public desire in China to improve its legislative oversight for regulating wildlife trade and consumption. Closing down the farms is only among the first steps. Much more can be done. We provide a few suggestions as follows.

As the government will probably not have sufficient resources and capacities to monitor the wildlife market over the long term, it is vital to encourage the participation of non-governmental organizations and the public. The public should have easy access to species information, their permitted uses and how to file a complaint, in order to facilitate detecting and reporting illegal cases. New technologies, such as machine learning, will also be helpful for species identification and handling public complaints.

Policymakers need to be aware of the adverse impacts of this ban on marginalized groups, and provide sufficient support to them. These groups should include, but not be limited to, segments of society that are still dependent on wildlife for essential protein, and wildlife farmers who are suffering economic hardships.

To further mitigate the risk of zoonotic disease transmission, it is also important to minimize our exposure to disease vectors and sources by halting further degradation and destruction of wildlife habitats. The establishment of a National Park system in China is an excellent opportunity to conserve natural ecosystems and manage human-wildlife interactions.

Through this crisis, China has the potential to be a global leader in managing domestic and international wildlife trade by expanding its domestic enforcement efforts to international trade, especially if it is related to the Chinese market. Particularly, when adjusting the national categories of protected animals, policymakers 
need to take into consideration existing international lists, such as the appendix of the Convention on International Trade in Endangered Species of Wild Fauna and Flora (CITES) and the International Union for Conservation of Nature (IUCN) Red List of Threatened Species. The Chinese ban may not be a perfect model for others, but every country could have some takeaways from its successes and challenges, and develop their own feasible and culturally nuanced solutions. In China's case, a ban is the right decision.

\section{Lian Pin Koh (DD $1 \times$, Yuhan $\mathrm{Li}^{2}$ and Janice Ser Huay Lee ${ }^{3}{ }^{3}$}

${ }^{1}$ Centre for Nature-based Climate Solutions, and Department of Biological Sciences, National University of Singapore, Singapore, Singapore. ${ }^{2}$ Interdisciplinary Centre for Conservation Science, Department of Zoology, and School of Geography and Environment, University of Oxford, Oxford, UK. ${ }^{3}$ Asian School of the Environment, Earth Observatory Singapore, Nanyang Technological University of Singapore, Singapore, Singapore.

$凶_{\boldsymbol{e} \text {-mail: lianpinkoh@nus.edu.sg }}$
Published online: 19 January 2021

https://doi.org/10.1038/s41893-020-00677-0

References

1. Zhang, M. Decision of the Standing Committee of the National People's Congress on Banning Illegal Wildlife Trade, the Consumption of Wild Animals and Protecting People's Health and Safety (The National People's Congress of the People's Republic of China, 2020); http://go.nature.com/3agU1Cy.

2. Hu, L. \& Bai, Y. Ban on illegal wildlife trade and consumption of wild animals - an interview with the Legal Work Committee of the Standing Committee of the National People's Congress. Xinhuanet (24 February 2020); http://go.nature.com/2LxNaud.

3. Notice of the Ministry of Agriculture and Rural Affairs on implementing the Decision of the Standing Committee of the National People's Congress to abolish the overconsumption of wild animals (Ministry of Agriculture and Rural Affairs of the People's Republic of China, 2020); http://go.nature.com/2IQH9I9

4. Dixon, M. WCS statement and analysis: on the Chinese government's decision prohibiting some trade and consumption of wild animals. WCS Newsroom (26 February 2020); http://go.nature.com/3akMXF0

5. Cheng, M. H. Lancet Infect. Dis. 7, 14 (2007).

6. Shen, Y. Report of the law enforcement inspection group of the Standing Committee of the National People's Congress on inspecting the implementation of the "Decision of the Standing Committee of the National People's Congress on banning illegal wildlife trade, the consumption of wild animals and protecting people's health and safety" and the Wildlife Protection Law (The National People's Congress of the People's Republic of China, 2020); http://go.nature.com/3af13HZ

7. Notice on Soliciting Public Opinions on the List of National Key Protected Species (2020); http://go.nature.com/3mhlV41.
8. Ministry of Agriculture and Rural Affairs announces National Animal Genetic Resources Catalog (Ministry of Agriculture and Rural Affairs, 2020); http://go.nature.com/3afljXt

9. Notice of the Ministry of Forestry and Grassland on the Classified Management of the Wild Animals Consumption Ban (Ministry of Forestry and Grassland, 2020); http://go.nature.com/3moPIaO

10. Guangdong Province Wildlife Protection and Management Regulations (Guangdong Provincial Department of Agriculture and Rural Affairs, 2020); https://go.nature.com/2IR3EwJ

11. Shenzhen becomes first Chinese city to ban eating cats and dogs. BBC (2 April 2020); http://go.nature.com/3mpCrPk

12. Leng, S. \& Wan, L. Pangolin officially removed from TCM list. Global Times (9 June 2020); http://go.nature.com/37kkyNs

13. Alberts, E. C. Did China really ban the pangolin trade? Not quite, investigators say. Mongabay (24 June 2020); http://go.nature. com/3oMbGpY

14. Zhang, L., Hua, N. \& Sun, S. Biodivers. Conserv. 17, 1493-1516 (2008).

15. Ribeiro, J., Bingre, P., Strubbe, D. \& Reino, L. Nature 578, 217 (2020).

16. Roe, D. et al. World Dev. 136, 105121 (2020).

17. Bonwitt, J. et al. Soc. Sci. Med. 200, 166-173 (2018).

18. Yu, C. Wildlife Protection Law of the People's Republic of China (The National People's Congress of the People's Republic of China, 2020); https://go.nature.com/3gPOww0

Acknowledgements

L.P.K. is supported by the Singapore National Research Foundation (NRF-RSS2019-007). Y.L. is supported by the Rhodes Scholarship.

Competing interests

The authors declare no competing interests. 